\title{
Selective coronary angiography, percutaneous coronary intervention and asymptomatic peri-procedural myocardial injury
}

\author{
Martin Griva ${ }^{\mathrm{a}, \mathrm{e}}$, Jiri Stastny ${ }^{\mathrm{a}}$, Petr Kopriva ${ }^{\mathrm{a}}$, Martin Slabak ${ }^{\mathrm{a}}$, Zdenek Coufal $^{\mathrm{a}}$, Jiri Jarkovsky ${ }^{\mathrm{b}}$, Michal Svoboda $^{\mathrm{b}}$, Tomas Salek \\ Lucie Sukupovad, Milos Taborsky ${ }^{\mathrm{e}}$
}

Background. While there have been a number of studies reporting the incidence and implications of elevated troponin levels after percutaneous coronary intervention ( $\mathrm{PCl}$ ), the body of information about the incidence, associations, and implications of elevated troponin levels following coronary angiography (CAG) is limited.

Materials and Methods. A total of 220 consecutive patients with stable coronary artery disease or intermediate or low-risk acute coronary syndrome without persistent ST-segment elevation (NSTE-ACS) were included in our study. High-sensitivity cardiac troponin I (hs-cTnl) levels were measured before and after coronary angiography (CAG) in patients with or without $\mathrm{PCl}$ and correlated with a number of clinical variables.

Results. Hs-cTnl elevations above the $99^{\text {th }}$ percentile upper reference limit (URL), or above $20 \%$ of the initially positive, yet already declining values, were found in 60 (37.2\%) patients after CAG and in 45 (76.2\%) patients undergoing PCI. Significant correlations of hs-cTnl elevation were found with the following variables: volume of contrast, fluoroscopy time, dose-area product, amount of contrast agent injected directly into the coronary arteries, total time of balloon dilation and the number and total length of implanted stents $(P<0.001$ for all).

Conclusion. While an asymptomatic elevation of hs-cTnl is a common finding after PCl, it does occur, quite surprisingly, also after CAG. Despite contradictory views regarding the clinical relevance of asymptomatic post-procedural elevated hs-cTnl levels, it is generally believed that a mild elevation is not associated with an increased risk. Still, it may pose a diagnostic quandary following a successful interventional procedure and even more so after an uncomplicated CAG. Trial Registration: Clinicaltrials.gov - NCT02960321

Key words: coronary angiography, percutaneous coronary intervention, high-sensitivity troponin, periprocedural myocardial injury

Received: July 22, 2018; Accepted: October 15, 2018; Available online: November 6, 2018 https://doi.org/10.5507/bp.2018.066

(c) 2019 The Authors. This is an open access article licensed under the Creative Commons Attribution License (https://creativecommons.org/licenses/by/4.0/).

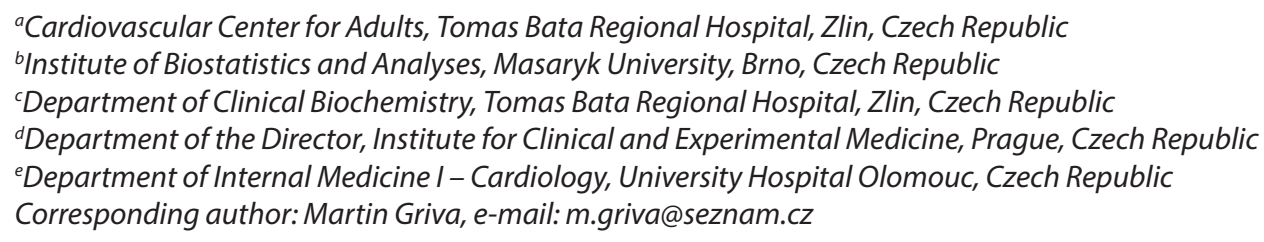

\section{INTRODUCTION}

Myocardial infarction (MI) as a sequel of percutaneous coronary intervention (PCI) meeting the criteria of the Third Universal Definition ${ }^{1}$ is quite a rare event in everyday practice. By contrast, PCI-related periprocedural myocardial injury is a relatively infrequent occurrence involving isolated elevation of myocardial necrosis markers in the absence of some other factors defining type 4a MI (ref. ${ }^{1}$ ). The body of literature data regarding the incidence and implications of asymptomatic plasma high-sensitivity cardiac troponin elevation following diagnostic coronary angiography (CAG) is limited ${ }^{2}$.

The aim of the present study was to compare the incidence of asymptomatic periprocedural myocardial injury after PCI versus CAG in everyday catheterization routine and search for any implications.

\section{MATERIALS AND METHODS}

Our prospective observational study (NCT02960321) initially included 226 consecutive patients assessed in a catheter laboratory from June through September 2016. Enrolled were patients with stable coronary disease or non-ST elevation acute coronary syndrome (NSTE-ACS) at intermediate or low risk with stable or already declining high-sensitivity cardiac troponin I (hs-cTnI) levels. Exclusion criteria included acute MI with persisting STsegment elevation, NSTE-ACS associated with very high or high risk or signs of ongoing ischemia ${ }^{3}$, and renal insufficiency.

Ineligible for inclusion were 6 patients $(2.7 \%)$ clearly classifiable as having experienced PCI-related MI by the Third Universal Definition of MI (type 4a MI). These patients showed clinical problems and ECG-documented 
ischemic lesions related to periprocedural occlusion of a branch or coronary artery dissection.

As a result, our study analyzed data of patients undergoing CAG followed immediately, in some cases, by uncomplicated PCI $(n=220)$.

At hospitalization, all study subjects signed informed consent for participation in the study. The study had been approved by a local ethics committee.

According to our planned procedure, patients were classified into the CAG or the PCI group. All procedure-related decisions including PCI were made at the discretion of an interventional cardiologist. In order to investigate any association between hs-cTnI release and the extent of coronary disease, SYNTAX score values were calculated.

\section{Laboratory investigations}

Baseline plasma hs-cTnI levels were determined at the hospital's Department of Clinical Biochemistry and Pharmacology using an Abbott ARCHITECT ci16 200 device (Abbott Laboratories, Abbott Park, Ill, USA) and an Abbott, High Sensitive Troponin-I Reagent Kit. The $99^{\text {th }}$ percentile (upper reference limit, URL) for men were set at $34 \mathrm{ng} / \mathrm{L}$ for men and $15 \mathrm{ng} / \mathrm{L}$ for women.

Blood samples obtained before the procedure and 17-20 h later were used to calculate absolute $\delta$-change between post-procedural hs-cTnI concentration and versus baseline levels (hs-cTnI post $_{-}$hs-cTnI $_{\text {baseline }}$ ) in $\mathrm{ng} / \mathrm{L}$, and relative $\delta$-change ([hs-cTnI ${ }_{\text {post }}-$ hs-cTnI $_{\text {baseline }}$ ) / hs-cTnIbaseline $\times 100)$ given as percentage change from baseline. A relevant increase in normal baseline hs-cTnI was defined as an elevation above the $99^{\text {th }}$ percentile URL, or for baseline hs-cTnI values >URL, a relative kinetic change (rise) of $20 \%$ or more.

The values were subsequently correlated against a number of clinical variables.

\section{Statistical analysis}

Standard descriptive statistics was applied in the analysis; median supplemented with the $5^{\text {th }}-95^{\text {th }}$ percen-

Table 1. Basic characteristics.

\begin{tabular}{|c|c|c|}
\hline Age (years) & & $69.0(50.5 ; 85.0)$ \\
\hline \multirow[t]{2}{*}{ Sex } & male & $\mathrm{n}=140(63.6)$ \\
\hline & female & $\mathrm{n}=80(36.4)$ \\
\hline Serum creatinine $(\mu \mathrm{mol} / 1)$ & & $86.0(60.0 ; 158.0)$ \\
\hline \multirow[t]{2}{*}{ Diabetes mellitus } & no & $\mathrm{n}=131(59.5)$ \\
\hline & yes & $\mathrm{n}=89(40.4)$ \\
\hline \multirow[t]{3}{*}{ Smoking } & no & $\mathrm{n}=129(58.6)$ \\
\hline & yes & $\mathrm{n}=34(15.5)$ \\
\hline & unknown & $\mathrm{n}=12(5.5)$ \\
\hline \multirow[t]{4}{*}{ SYNTAX score } & 0 & $\mathrm{n}=82(40.4)$ \\
\hline & $1-23$ & $\mathrm{n}=76(37.4)$ \\
\hline & $24-32$ & $\mathrm{n}=26(12.8)$ \\
\hline & $33+$ & $\mathrm{n}=19(9.4)$ \\
\hline \multirow[t]{2}{*}{ Coronary artery bypass grafting } & no & $\mathrm{n}=203(92.3)$ \\
\hline & yes & $\mathrm{n}=17(7.7)$ \\
\hline Left ventricular ejection fraction (\%) & & $55.0(25.0 ; 67.0)$ \\
\hline \multirow[t]{4}{*}{ Type of contrast agent } & iomeprol & $\mathrm{n}=93(42.3)$ \\
\hline & iopromide & $\mathrm{n}=62(28.2)$ \\
\hline & ioversol & $\mathrm{n}=14(6.4)$ \\
\hline & iodixanol & $\mathrm{n}=51(23.2)$ \\
\hline Volume of contrast used (ml) & & $75.0(30.0 ; 277.5)$ \\
\hline Fluoroscopy time (s) & & $225.5(63.5 ; 1270.5)$ \\
\hline Dose-area product (DAP) (mGy.cm²) & & $47963.0(17228.5 ; 182358.5)$ \\
\hline \multirow[t]{2}{*}{ Left ventriculography } & no & $\mathrm{n}=111(50.5)$ \\
\hline & yes & $\mathrm{n}=109(49.5)$ \\
\hline Total time of balloon dilatation (s) & & $0.0(0.0 ; 110.5)$ \\
\hline Total length of implanted stents ( $\mathrm{mm}$ ) & & $0.0(0.0 ; 44.0)$ \\
\hline \multirow[t]{2}{*}{ Diagnostic catheter size } & $5 \mathrm{~F}$ & $\mathrm{n}=176(80.0)$ \\
\hline & $6 \mathrm{~F}$ & $\mathrm{n}=44(20.0)$ \\
\hline Number of angiographic series & & $9.0(7.0 ; 23.0)$ \\
\hline $\begin{array}{l}\text { Volume of contrast injected } \\
\text { into coronary arteries }(\mathrm{ml})\end{array}$ & & $26.1(19.6 ; 64.6)$ \\
\hline \multirow[t]{2}{*}{ Statin pretreatment } & no & $\mathrm{n}=66(30.0)$ \\
\hline & yes & $\mathrm{n}=154(70.0)$ \\
\hline
\end{tabular}

Median supplemented with the $5^{\text {th }}-95^{\text {th }}$ percentile range for continuous data; absolute and relative frequencies for categorical data. 
tile range for continuous data, and absolute and relative frequencies for categorical data. Statistical significance of differences in continuous variables between the subgroups of patients was tested using the Mann-Whitney U test or Kruskal-Wallis test; the relation between continuous variables was described using Spearman rank correlation coefficient and its statistical significance. Statistical analysis was computed using IBM SPSS Statistics for Windows, Version 24.0.0.1 (IBM Corporation released 2016, Armonk, NY).

\section{RESULTS}

While a total of 161 patients $(73.2 \%)$ had diagnostic CAG alone, in 59 patients $(26.8 \%)$ CAG was immediately followed by PCI. In 157 patients $(71.4 \%)$ baseline hs-cTnI was negative $\left(<99^{\text {th }}\right.$ percentile URL).

Basic characteristics of our entire study population are shown in Table 1.

Main indications for CAG included exertional angina (36\%), NSTE-ACS (18.7\%), heart failure (17.7\%), severe valve disease $(7.7 \%)$, silent myocardial ischemia $(4.5 \%)$, malignant arrhythmias (4.1\%), staged PCI (3.6\%), and other $(7.8 \%)$.

In the entire study population, the baseline hs-cTnI median was $10 \mathrm{ng} / \mathrm{L}$ (2-753) without statistically significant differences between the CAG and PCI groups.

Periprocedural asymptomatic elevation of hs-cTnI levels above the $99^{\text {th }}$ percentile URL or above $20 \%$ of initially positive values was observed in $76.2 \%$ patients post PCI (Table 2), but, quite surprisingly, also in $37.2 \%$ patients undergoing diagnostic CAG (Table 3).

The proportions of patients experiencing periprocedural elevations were very similar in the subgroup of patients with originally initially negative hs-cTnI compared with those showing stable elevated levels at baseline.

In the subgroup of patients with negative hs-cTnI at baseline, the median absolute change in hs-cTnI was 119 ( $5^{\text {th }}$ to $95^{\text {th }}$ percentile: $\left.3 ; 1,989\right)$ in the PCI-subgroup, and $5(-2 ; 165)$ in the CAG-only subgroup.

In a total of $44.7 \%$ of patients having PCI and $8.4 \%$

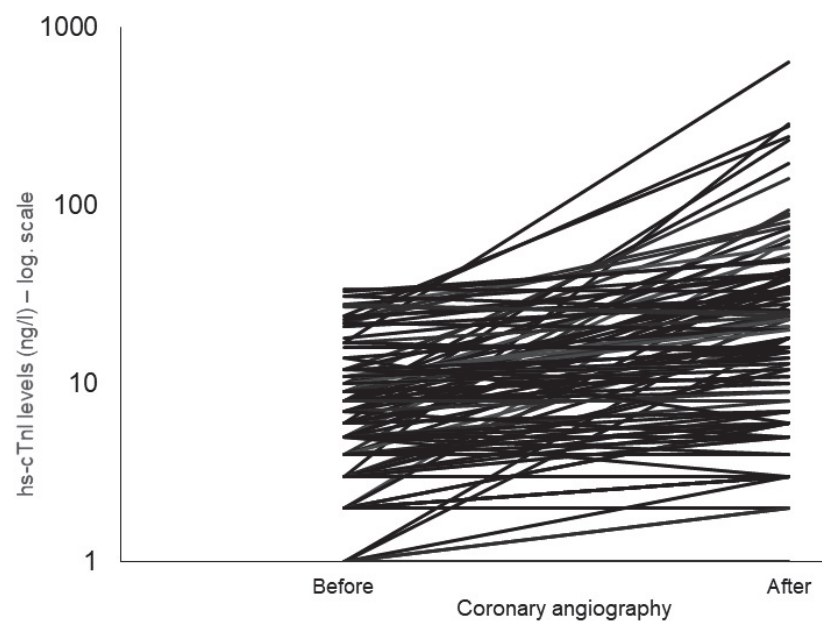

Fig. 1. Absolute change in hs-cTnI levels in patients with initially negative values $(n=119)$.

of those undergoing CAG only, hs-cTnI levels increased to even more than five times the URL from the initially negative values (Table 2 and 3 ).

Absolute changes in hs-cTnI in the subgroup of patients undergoing CAG and having initially negative values are given in Fig. 1.

Correlations between the relative change in hs-cTnI and variables assessed in the entire study population are shown in Tables 4 and 5.

The relative increase in hs-cTnI levels seen in the PCI subgroup correlates statistically significantly with the number of implanted stents, their total length, and total balloon dilatation times.

In our entire study population, the relative hs-cTnI elevation correlated significantly with left ventricular ejection fraction, total amount of the contrast agent injected directly into the coronary territory, number of angiographic sequences, fluoroscopy time and dose-area product.

No statistically significant differences in hs-cTnI elevations among PCI operators were documented. Likewise, no clear association was demonstrated between elevated troponin levels on the one hand and baseline diagnosis

Table 2. Elevation of hs-cTnI in the CAG + PCI subgroup.

\begin{tabular}{lllll}
\hline & & $\begin{array}{l}\text { Elevation of hs-cTnI }>99^{\text {th }} \\
\text { percentile URL } \\
\text { post-PCI }\end{array}$ & $\begin{array}{l}\text { Elevation of hs-cTnI }>5 \times \\
99^{\text {th }} \text { percentile URL } \\
\text { post-PCI }\end{array}$ & $\begin{array}{l}\text { Rise of hs-cTnI levels }>20 \% \\
\text { above baseline value } \\
\text { post-PCI }\end{array}$ \\
\hline All & $\mathrm{n}=59$ & $\mathrm{n}=45(76.2 \%)$ & $\mathrm{n}=33(55.9 \%)$ & \\
Initially negative hs-cTnI & $\mathrm{n}=38$ & $\mathrm{n}=29(76.3 \%)$ & $\mathrm{n}=17(44.7 \%)$ & $\mathrm{n}=16(76.2 \%)$ \\
Initially positive hs-cTnI & $\mathrm{n}=21$ & & & \\
\hline
\end{tabular}

Table 3. Elevation of hs-cTnI in the CAG-only subgroup.

\begin{tabular}{lllll}
\hline & & $\begin{array}{l}\text { Elevation of hs-cTnI }>99^{\text {th }} \\
\text { percentile URL } \\
\text { post-CAG }\end{array}$ & $\begin{array}{l}\text { Elevation of hs-cTnI }>5 \times \\
99^{\text {th }} \text { percentile URL } \\
\text { post-CAG }\end{array}$ & $\begin{array}{l}\text { Rise of hs-cTnI levels }>20 \% \\
\text { above baseline value } \\
\text { post-CAG }\end{array}$ \\
All & $\mathrm{n}=161$ & $\mathrm{n}=60(37.2 \%)$ & $\mathrm{n}=27(16.6 \%)$ & \\
Initially negative hs-cTnI & $\mathrm{n}=119$ & $\mathrm{n}=43(36.1 \%)$ & $\mathrm{n}=10(8.4 \%)$ & $\mathrm{n}=17(40.5 \%)$ \\
Initially positive hs-cTnI & $\mathrm{n}=42$ & & & \\
\hline
\end{tabular}


Table 4. Dependence of relative change in hs-cTnI on monitored variables (categorical data).

\begin{tabular}{|c|c|c|c|c|c|c|}
\hline & & $\mathrm{n}$ & $\begin{array}{c}\text { Median } \\
(\%)\end{array}$ & $5^{\text {th }}$ percentile & $95^{\text {th }}$ percentile & $P$ \\
\hline \multirow[t]{2}{*}{ Sex } & male & 140 & 95 & -24 & 4538 & 0.226 \\
\hline & female & 80 & 142 & -25 & 3114 & \\
\hline \multirow[t]{2}{*}{ Diabetes mellitus } & no & 131 & 114 & -17 & 6920 & 0.531 \\
\hline & yes & 89 & 93 & -29 & 3210 & \\
\hline \multirow[t]{2}{*}{ Smoking } & no & 129 & 100 & -22 & 3783 & 0.779 \\
\hline & yes & 34 & 46 & -26 & 11,500 & \\
\hline \multirow[t]{4}{*}{ SYNTAX score } & 0 & 82 & 101 & -19 & 2000 & \\
\hline & $1-23$ & 76 & 122 & -26 & 7071 & 0.295 \\
\hline & $24-32$ & 26 & 291 & -44 & 28,414 & \\
\hline & $33+$ & 19 & 38 & -38 & 3425 & \\
\hline \multirow[t]{2}{*}{ Coronary artery bypass grafting } & no & 203 & 100 & -23 & 4290 & 0.893 \\
\hline & yes & 17 & 75 & -38 & 2975 & \\
\hline \multirow[t]{4}{*}{ Type of contrast used } & iomeprol & 93 & 50 & -29 & 7071 & \\
\hline & iopromide & 62 & 235 & -4 & 3060 & 0.058 \\
\hline & ioversol & 14 & 166 & -9 & 1700 & \\
\hline & iodixanol & 51 & 100 & -27 & 3671 & \\
\hline \multirow[t]{2}{*}{ Left ventriculography } & no & 111 & 100 & -27 & 3425 & 0.372 \\
\hline & yes & 109 & 114 & -16 & 11,325 & \\
\hline \multirow[t]{3}{*}{ Number of implanted stents } & 0 & 164 & 50 & -26 & 2000 & \\
\hline & 1 & 39 & 415 & -10 & 21,050 & $<0.001$ \\
\hline & $2+$ & 17 & 1280 & -27 & 74,755 & \\
\hline \multirow[t]{2}{*}{ Diagnostic catheter size } & $5 \mathrm{~F}$ & 176 & 100 & -26 & 3783 & 0.282 \\
\hline & $6 \mathrm{~F}$ & 44 & 128 & -9 & 4290 & \\
\hline \multirow[t]{2}{*}{ Statin pre-treatment } & no & 66 & 220 & -14 & 3140 & 0.281 \\
\hline & yes & 154 & 96 & -26 & 4787 & \\
\hline \multirow[t]{2}{*}{ Procedure } & CAG & 161 & 50 & -26 & 1700 & $<0.001$ \\
\hline & $\mathrm{CAG}+\mathrm{PCI}$ & 59 & 489 & -23 & 21,059 & \\
\hline
\end{tabular}

Median supplemented with the 5th-95th percentile range for continuous data; statistical significance of differences among groups tested by the Mann-Whitney U test or Kruskal-Wallis test

Table 5. Dependence of relative change in hs-cTnI on monitored variables (continuous data).

\begin{tabular}{lcr}
\hline & Spearman correlation & $P$ \\
\hline Age & 0.045 & 0.509 \\
Hematocrit & 0.085 & 0.209 \\
Creatinine & -0.068 & 0.318 \\
Body weight & -0.037 & 0.582 \\
Left ventricular ejection fraction (by echocardiography) & 0.140 & $\mathbf{0 . 0 4 1}$ \\
Volume of contrast used & 0.360 & $\mathbf{< . 0 0 1}$ \\
Fluoroscopic time & 0.361 & $\mathbf{< . 0 0 1}$ \\
Dose area product & 0.275 & $\mathbf{< . 0 0 1}$ \\
PCI - total balloon dilatation time & 0.381 & $\mathbf{< 0 . 0 0 1}$ \\
PCI - total length of implanted stents & 0.379 & $\mathbf{< 0 . 0 0 1}$ \\
Number of angiographic sequences & 0.352 & $\mathbf{< 0 . 0 0 1}$ \\
Estimated amount of contrast injected into coronary territory & 0.345 & $\mathbf{< 0 . 0 0 1}$ \\
Heart rate before procedure & -0.083 & 0.218 \\
Systolic blood pressure before procedure & 0.119 & 0.078 \\
Systolic blood pressure after procedure & 0.066 & 0.332 \\
\hline
\end{tabular}

prompting PCI or some biometric and laboratory data on the other; neither was a correlation shown between post-procedural hs-cTnI elevation and the SYNTAX score.

\section{DISCUSSION}

The importance of troponin for heart contractions was described as early as 40 years ago ${ }^{4}$. Troponins have been used to diagnose acute coronary syndrome since the 1990s, with increasingly sensitive techniques allowing for 
detection of increasingly lower levels of cardiac troponins in the peripheral blood increasing, in turn, the need for correct clinical interpretation of their positivity.

The most common causes of troponin release from the myocardium include necrosis, apoptosis ${ }^{5,6}$, or mechanical damage to myocardial cells ${ }^{7}$.

While the bulk of troponin in the cardiac myocyte (92-93\%) is bound to the troponin-tropomyosin complex, there is a small pool of unbound TnT or TnI in the cytosol $(6-8 \%)$. The role and mechanism of formation of the cytosol fraction are still poorly understood. The molecular weight and immune reactivity of cytosol-based and bound troponins are identical. The cytosol fraction of cardiac troponins is also the first to release into the circulation following cardiac myocyte sarcolemma injury ${ }^{8}$. This particular fraction is detected in the early phase of ischemia, most often within $48 \mathrm{~h}$. Once more severe or prolonged ischemia has developed, the cardiac myocyte becomes necrotic with subsequent proteolytic degradation of the troponin-tropomyosin complex responsible for the release of the bound troponin fraction. In such cases, troponin levels remain elevated for 10-14 days due to progressive myofibril degradation and breakup of the troponin- complex ${ }^{9}$.

Cardiac troponin levels may initially vary within minutes and differ significantly at different points of the circulation (as seen, e.g., when measuring troponin levels simultaneously in the coronary sinus and radial artery) $\left(\right.$ ref. ${ }^{10}$ ). The possibility of rapid changes in troponin levels following the development and discontinuation of ischemia provides indirect evidence that an early elevation of troponin levels may not necessarily signal cardiac myocyte necrosis.

The mechanism of release of a small amount of troponin from the cytosol into the circulation consists of the formation of membrane sacs (blebs) transporting, in the early phase of ischemia, macromolecules for which the cytoplasmic membrane is otherwise impermeable. The result is release of the cytoplasmic troponin pool. If the ischemia is only transient with perfusion resumed before irreversible changes have developed, the integrity of the cytoplasmic membrane is not impaire ${ }^{11}$. In clinical practice, these short-lasting mild elevations in troponin levels may go undetected unless blood samples are obtained just at the time of troponin release.

On the other hand, high-resolution imaging techniques such as contrast-enhanced MRI have established that even small biomarker elevations reflect myonecrosis ${ }^{12}$. In a cohort with complex lesions, PCI resulted in a mean loss of $1.7 \pm 4.0 \mathrm{~g}$ of myocardial tissue. All of these patients showed elevated cTnI levels (range 1000 to $9400 \mathrm{ng} / \mathrm{L}$ ). There was a strong correlation between the rise in cTnI levels at 24 hours and mean mass of new myocardial hyperenhancement after PCI (ref. ${ }^{13}$ ). However, the above range of values clearly suggests that the notion of "small elevations" is most relative.

Consensus could perhaps be reached in the explanation that although the true half-life of both troponins in the circulation is short - on the order of $2 \mathrm{~h}$ - the clinical half-life of both troponins is substantially longer due to the continued leaching of troponin from the remains of the necrotic cell. A clinical half-life of $\geq 20 \mathrm{~h}$ is the hallmark of cardiac myocyte necrosis ${ }^{11,14}$.

In all of our patients, blood samples were drawn within $20 \mathrm{~h}$ of CAG or PCI. Elevated hs-cTnI levels in the order of tens to hundreds of $\mathrm{ng} / \mathrm{L}$ were documented particularly in patients undergoing CAG. This finding indirectly supports our theory that it is the cytoplasmic troponin fraction which is actually detected. The question to be yet answered is the mechanism, in various invasive cardiac procedures in cardiology, of inducing hs-TnI elevation in cases whereby intraprocedural myocardial ischemia is unlikely to occur.

In their study, Hnatek et al. ${ }^{7}$ documented significantly elevated hs-cTnI levels associated with pacemaker implantation. Troponin elevation correlated with fluoroscopy time used by the authors as an indirect marker of the complexity of the procedure involving active lead fixation ${ }^{7}$. An interesting finding reported by Boos et al. was that, during pacemaker implantation using leads without active fixation, the only factor correlating with troponin elevation was also fluoroscopy time required for lead implantation. The authors suggested the elevated troponin levels were due to mild reversible myocardial injury sustained during manipulation with pacing leads in the right ventricle ${ }^{9}$.

Our study showed a significant correlation of relative hs-cTnI elevations with fluoroscopy time, dose-area product, and number of angiographic series in both subgroups, i.e., those with only diagnostic assessment (CAG) or coronary intervention (PCI). The implication could be that the factor triggering troponin release were x-rays per se.

However, based on the currently available body of information, it is more than likely that cardiac myocyte necrosis is not due to the radiation doses commonly used during invasive cardiac procedures. While, generally, radiation may induce a broad spectrum of cardiovascular pathologies through various mechanisms ${ }^{15}$, doses resulting in myocardial injury have been shown by observational studies to be many times higher than those required for interventional procedures. In patients undergoing radiation therapy for a malignancy, no significant increase in the risk for doses $<5$ Gy has been reported ${ }^{16,17}$. Experimental studies have shown that, while endothelial cells are sensitive to radiation, expression of inflammatory adhesive molecules is only induced by doses $\geq 2$ Gy (ref. ${ }^{18,19}$ ). A lifespan study of atomic bomb survivors did not document a significant increase in their cardiovascular risk after a radiation dose $<0.5 \mathrm{~Gy}\left(\right.$ ref. $\left.^{20}\right)$. The implication is that the increase in troponin levels depending on fluoroscopy time or radiation dose rather reflects the length and complexity of the procedure and/or another concomitant factor.

It follows from the very principle of CAG that the technique combines radiation with injection of a contrast agent into the coronary territory. In all subgroups of our study (CAG, PCI, negative baseline hs-cTnI levels, and increased baseline hs-cTnI levels), statistical analysis revealed a correlation between relative increase in hs-cTnI levels and the amount of the contrast agent used and/or injected into the coronary arteries). A similar conclusion was reported by Abu Sharar et al. ${ }^{2}$. The mechanism where- 
by the contrast agent induces troponin release from the cardiac myocyte is unclear. Likely explanations include transient short-term myocardial ischemia, short-term pressure overload at the level of microcirculation, tiny plaque erosions together with peripheral microembolism, or relative cardiac toxicity, among others. A less likely cause is osmotic pressure of the contrast on the myocardium as post-procedural hs-cTnI elevations did not vary based on the osmolality of the contrast agent used.

While studies investigating troponin elevations following diagnostic CAG are scarce, extensive research has documented elevated markers of myocardial necrosis associated with PCI. The large number of published studies differ in the study population size and methodology; hence the relatively large variability of results. Periprocedural myocardial injury occurs in 5-30\% of PCI-treated patients ${ }^{21}$. In contrast to earlier studies, troponin levels in our study were determined using a highly sensitive technique which explains the substantially higher proportion of patients with periprocedural troponin elevation.

Besides known PCI-related complications such as coronary artery dissection, arterial branch occlusion, peripheral embolism, etc., the causes of troponin elevation may be similar to those developing after CAG alone (use of contrast agent). An additional role may be played by intermittent ischemia in the coronary territory due to balloon dilatation, peripheral microembolism caused by plaque debris (while possibly undetectable by CAG and not necessarily having a clinical correlate) or occlusion of tiny arterial branches the size of which is beyond the detection capacity of CAG. All the above is supported by our finding of a correlation between hs-cTnI elevation in the PCI subgroup on the one hand, and total time of balloon dilatation and total length of implanted stents on the other.

There are largely divergent views on the clinical and prognostic relevance of periprocedural troponin elevation. Some authors have suggested that even an isolated minor elevation in cTnT after PCI provides long-term prognostic information regarding mortality and myocardial infarction incidence ${ }^{22}$. A meta-analysis published in 2008 found that increased mortality was significantly associated with troponin elevation after PCI. Furthermore, the combined endpoint of mortality or nonfatal myocardial infarction also occurred more often in patients with post-procedural troponin elevation. According to this meta-analysis, troponin elevation after elective PCI provides important prognostic information ${ }^{23}$.

Other reports highlighted the importance of particular troponin levels, as patients with elevation $>3 \times$ the URL are at high risk of further adverse events both during hospital stay and at 18 months after discharge. Patients with elevation of troponin less than $3 \times$ the URL did not have a worse prognosis during follow-up ${ }^{24}$.

Data from recent research tend to support the conclusion that the independent prognostic value for cardiac biomarkers of any cut-off showed no statistical significance for all-cause mortality, whereas the combined endpoint (all-cause mortality or new-onset heart failure) were ambiguous in both short- and long-term follow-up ${ }^{25,26}$.

Another most important finding is that long-term prognosis is most often related to the baseline pre-PCI troponin value and not the biomarker response to the PCI. These results support a re-evaluation of the use of biomarker data in relation to PCI (ref. ${ }^{27,28}$ ). Pre-procedural troponin levels likely mirror the extent of coronary involvement as suggested by studies searching for any association between baseline troponin levels and the SYNTAX score $^{29,30}$. However, no statistically significant association between post-procedural troponin elevation and the SYNTAX score was found in our study.

Likewise, no potential protective effect of statins was demonstrated despite divergent literature data in this respect $^{31,32}$. Explanations for this may include differences between our two study subgroups and likely pathophysiology of troponin elevation. In our PCI subgroup, virtually all patients received pre-treatment with statins thus ruling out statistical evaluation. In the CAG subgroup, troponin elevation was likely due to a cause other than statin use.

\section{Study limitations}

A limitation of our study was the absence of further plasma hs-cTnI level measurements at longer time intervals. Any low values would have supported the hypothesis that troponin elevation is not due to cardiac myocyte necrosis but only to cytosol troponin fraction release.

Another limitation is the failure to continuously monitor ST-segment changes which may be dynamic. A single routine ECG test may leave such changes undetected unless a patient 's condition prompts another ECG test. One may ask what the interpretation of hs-cTnI elevation in the presence of transient ST-segment changes would be and whether our conclusions would not be completely different.

\section{CONCLUSIONS}

While an asymptomatic elevation of hs-cTnI is a common finding after PCI, quite surprisingly it also does occur after CAG. Mild asymptomatic post-procedural cardiac troponin elevations are likely due to cytosol troponin fraction release and not to extensive cardiac myocyte necrosis. The clinical implications of mild troponin elevations after interventional cardiac procedures are subject of controversy. While, in asymptomatic patients showing no other signs of ongoing myocardial ischemia, mild troponin elevation has most probably no effect on left ventricular function or arrhythmogenesis to directly impair survival, it may pose a diagnostic quandary following a successful interventional procedure and even more so after uncomplicated coronary angiography.

Acknowledgement: This publication was supported by the AVAST Foundation - Together till the end.

Author contributions: MG: study design, manuscript drafting; MG, JS, PK, MS, ZC: Acquisition of the data; JJ,MS: 
data analysis; MG, TS, LS: interpretation of the analysis; MT: critical revision; All authors had full access to the data and approved the manuscript before submitting it. Conflict of interest statement: The authors state that there are no conflicts of interest regarding the publication of this article.

\section{REFERENCES}

1. Thygesen K, Alpert JS, Jaffe AS, Simoons ML, Chaitman BR, White HD. Joint ESC/ACCF/AHA/WHF Task Force for Universal Definition of Myocardial Infarction. Third universal definition of myocardial infarction. Eur Heart J 2012;33(20):2551-67.

2. Abu Sharar $H$, Wohlleben D, Vafaie M, Kristen AV, Volz HC, Bekeredjian R, Katus HA, Giannitsis E. Coronary angiography-related myocardial injury as detected by high-sensitivity cardiac troponin T assay. Eurolntervention 2016;12(3):337-44.

3. Roffi M, Patrono C, Collet J-P, Mueller C, Valgimigli M, Andreotti F, Bax $\mathrm{JJ}$, Borger MA, Brotons C, Chew DP, Gencer B, Hasenfuss G, Kjeldsen K, Lancellotti P, Landmesser U, Mehilli J, Mukherjee D, Storey RF, Windecker S. 2015 ESC Guidelines for the management of acute coronary syndromes in patients presenting without persistent ST-segment elevation: Task Force for the Management of Acute Coronary Syndromes in Patients Presenting without Persistent STSegment Elevation of the European Society of Cardiology (ESC). Eur Heart J 2016;37(3):267-315.

4. Hartshorne DJ. Interactions of Desensitized Actomyosin with Tropomyosin, Troponin A, Troponin B, and Polyanions. J Gen Physiol 1970;55(5):585-601.

5. Perna ER, Macín SM, Cimbaro Canella JP, Alvarenga PM, Ríos NG, Pantich R, Augier N, Farías EF, Jantus E, Brizuela M, Medina F. Minor myocardial damage detected by troponin $\mathrm{T}$ is a powerful predictor of long-term prognosis in patients with acute decompensated heart failure. Int J Cardiol 2005;99(2):253-61.

6. Horowich TB, Patel J, MacLellan WR, Fonarow GC. Cardiac troponin I is associated with impaired hemodynamics, progressive left ventricular dysfunction, and increased mortality rates in advanced heart failure. Circulation 2003;108(7):833-8.

7. Hnátek T, Táborský $M$, Malý $M$, Kameník $L$, Littnerová $S$, Sedloň $P$, Luxová J, Fišerová M, Hamouzová Š, Zavoral M. Troponiny a minimální myokardiální poškození po primoimplantaci kardiostimulátoru - pilotní studie. Interv Akut Kardiol 2015;14(1):14-7 (In Czech).

8. Bleier J, Vorderwinkler KP, Falkensammer J, Mair P, Dapunt O, Puschendorf B, Mair J. Different intracellular compartmentations of cardiac troponins and myosin heavy chains: a causal connection to their different early release after myocardial damage. Clin Chem 1998;44(9):1912-8.

9. Boos CJ, Gough S, Wheather M, Medbak S, More R. Effects of Transvenous Pacing on Cardiac Troponin Release. PACE 2004;27(9):1264-8.

10. Suleiman MS, Lucchetti V, Caputo M, Angelini GD. Short periods of regional ischaemia and reperfusion provoke release of troponin I from the human hearts. Clin Chim Acta 1999;284(1):25-30.

11. Hickman PE, Potter JM, Aroney C, Koerbin G, Southcott E, Wu AHB, Roberts MS. Cardiac troponin may be released by ischemia alone, without necrosis. Clin Chim Acta 2010;411(5-6):318-23.

12. Lansky AJ, Stone GW. Periprocedural myocardial infarction: prevalence, prognosis, and prevention. Circ Cardiovasc Interv 2010;3(6):602-10.

13. Selvanayagam JB, Porto I, Channon K, Petersen SE, Francis JM, Neubauer S, Banning AP. Troponin elevation after percutaneous coronary intervention directly represents the extent of irreversible myocardial injury: insights from cardiovascular magnetic resonance imaging. Circulation 2005;111(8):1027-32.

14. Gerhardt W, Katus H, Ravkilde J, Hamm C, Jørgensen PJ, Peheim E, Ljungdahl L , Lofdahl P. S-troponin T in suspected ischemic myocardial injury compared with mass and catalytic concentrations of S-creatine kinase isoenzyme MB. Clin Chem 1991;37(8):1405-11.

15. Stewart FA, Seemann I, Hoving S, Russell NS. Understanding radiation-induced cardiovascular damage and strategies for intervention. Clin Oncol (R Coll Radiol) 2013;25(10):617-24.
16. Mulrooney DA, Yeazel MW, Kawashima T, Mertens AC, Mitby $P$, Stovall M, Donaldson SS, Green DM, Sklar CA, Robison LL, Leisenring WM. Cardiac outcomes in a cohort of adult survivors of childhood and adolescent cancer: retrospective analysis of the Childhood Cancer Survivor Study cohort. BMJ 2009;339:b4606.

17. Tukenova M, Guibout $C$, Oberlin O, Doyon F, Mousannif A, Haddy N, Guérin S, Pacquement H, Aouba A, Hawkins M, Winter D, Bourhis J, Lefkopoulos D, Diallo I, de Vathaire F. Role of cancer treatment in long-term overall and cardiovascular mortality after childhood cancer. J Clin Oncol 2010;28(8):1308-15.

18. Little MP, Tawn EJ, Tzoulaki I, Wakeford R, Hildebrandt G, Paris F, Tapio S, Elliott P. A systematic review of epidemiological associations between low and moderate doses of ionizing radiation and late cardiovascular effects, and their possible mechanisms. Radiat Res 2008;169(1):99-109.

19. Khaled S, Gupta KB, Kucik DF. lonizing radiation increases adhesiveness of human aortic endothelial cells via a chemokine-dependent mechanism. Radiat Res 2012;177(5):594-601.

20. Shimizu Y, Pierce DA, Preston DL, Mabuchi K. Studies of the mortality of atomic bomb survivors. Report 12, part II. Noncancer mortality: 1950-1990. Radiat Res 1999;152(4):374-89.

21. Cuculi F, Lim CCS, Banning AP. Periprocedural myocardial injury during elective percutaneous coronary intervention: is it important and how can it be prevented? Heart 2010;96(10):736-40.

22. Prasad A, Singh $M$, Lerman A, Lennon RJ, Holmes DR, Rihal CS. Isolated elevation in troponin $\mathrm{T}$ after percutaneous coronary intervention is associated with higher long-term mortality. J Am Coll Cardiol 2006;48(9):1765-70.

23. Nienhuis MB, Ottervanger JP, Bilo HJG, Dikkeschei BD, Zijlstra F. Prognostic value of troponin after elective percutaneous coronary intervention: A meta-analysis. Catheter Cardiovasc Interv 2008;71(3):318-24.

24. Testa L, Van Gaal WJ, Biondi Zoccai GGL, Agostoni P, Latini RA, Bedogni F, Porto I, Banning AP. Myocardial infarction after percutaneous coronary intervention: a meta-analysis of troponin elevation applying the new universal definition. QJM 2009;102(6):369-78.

25. Christensen MK, Huang H, Torp-Pedersen C, Trydal T, Ravkilde J. Incidence and impact on prognosis of peri-procedural myocardial infarction in 2760 elective patients with stable angina pectoris in a historical prospective follow-up study. BMC Cardiovasc Disord 2016;16:140.

26. Zhang M, He H, Wang Z-M, Xu Z, Zhou N, Tao Z, Chen B, Li C, Zhu $T$, Yang D, Wang L, Yang Z. Diagnostic and prognostic value of minor elevated cardiac troponin levels for percutaneous coronary intervention-related myocardial injury: a prospective, single-center and double-blind study. J Biomed Res 2014;28(2):98-107.

27. Miller WL, Garratt KN, Burritt MF, Lennon RJ, Reeder GS, Jaffe AS Baseline troponin level: key to understanding the importance of post-PCI troponin elevations. Eur Heart J 2006;27(9):1061-9.

28. Prasad A, Rihal CS, Lennon RJ, Singh M, Jaffe AS, Holmes DR. Significance of periprocedural myonecrosis on outcomes after percutaneous coronary intervention: an analysis of preintervention and postintervention troponin T levels in 5487 patients. Circ Cardiovasc Interv 2008;1(1):10-9.

29. Daněk J, Hnátek T, Malý $M$, Táborský $M$, Běláček J, Škvaril J, Pospíšilová L, Černohous M, Sedloň P, Hajšl M, Zavoral M. Troponin levels in patients with stable CAD. Cor Vasa 2017;59(3):e229-34.

30. Yamazaki K, lijima R, Nakamura M, Sugi K. High-sensitivity cardiac troponin $T$ level is associated with angiographic complexity of coronary artery disease: a cross-sectional study. Heart Vessels 2016;31(6):890-6

31. Pasceri V, Patti G, Nusca A, Pristipino C, Richichi G, Di Sciascio G; ARMYDA Investigators. Randomized trial of atorvastatin for reduction of myocardial damage during coronary intervention: results from the ARMYDA (Atorvastatin for Reduction of MYocardial Damage during Angioplasty) study. Circulation 2004;110(6):674-8.

32. Veselka J, Zemánek D, Hájek P, Malý M, Adlová R, Martinkovicová L, Tesar D. Effect of two-day atorvastatin pretreatment on the incidence of periprocedural myocardial infarction following elective percutaneous coronary intervention: a single-center, prospective, and randomized study. Am J Cardiol 2009;104(5):630-3. 